\title{
Psychiatric Rehabilitation Updated
}

These recommendations to the College from the Social and Community Psychiatry Section have been agreed by the Court of Electors.

\section{Psychiatric rehabilitation}

The term 'psychiatric rehabilitation' should be regarded as having wide meaning with many components. All treatment programmes should include a rehabilitation plan. This may be based on helping the patient to adjust to the original environment, or it may require an enabling programme in a caring, supportive environment to help people achieve, or maintain, optimal levels of well-being. The assistance of staff experienced in rehabilitation techniques may be required at some stage.

Rehabilitation services should be provided particularly for persons who are severely disabled by chronic mental disorder. In general, the service should be available on a district, rather than a sector basis, but this will depend on local circumstances.

\section{Training}

The training of all staff engaged in the mental health services should include experience in the rehabilitation and management of chronic mental disorder. This should involve not simply work in long-stay wards but experience of structured progressive rehabilitation programmes spanning a range of activities in hospital and in statutory and voluntary community agencies.

College Approval Panels should ensure that equal weight is given to training in rehabilitation as to other rotational posts. MRCPsych courses should include appropriate teaching on rehabilitation by staff experienced in the subject and the MRCPsych examination should test knowledge in this area.

Senior registrars with an interest in this aspect should have the opportunity of 12 months special experience in rehabilitation for consultant training. This may require secondment if no suitable experience is available.

Appointments of new consultants with major responsibility for rehabilitation should be conditional on such experience. If there is no candidate with suitable rehabilitation experience, a general psychiatrist may be appointed with the understanding that he/she is given sufficient study leave to rectify this deficiency.

Training in management skills, although important for all consultants, is particularly necessary for a rehabilitation consultant who must work with multi-disciplinary teams and who must be involved in planning and managing services.

\section{Community resources}

There is a need for a community approach to rehabilitation, as well as a hospital-centred approach. All District Health Authorities and Area Health Boards should be jointly accountable, with their respective Local Authorities, for the creation, funding and management of an adequate range of services for people with chronic mental disorder. They should also work in close liaison with voluntary organisations, including housing associations.

A District Rehabilitation Committee is a key structure and should have the tasks of researching local needs, producing a local plan and seeking appropriate funding.

Such district committees should include as key members the consultant psychiatrist with special responsibility for rehabilitation, a community physician, an assistant director of social services and a senior housing department officer, together with representatives of the other professions and agencies involved.

This committee should be involved in the transfer of resources from the mental hospital to community services.

The real problem is that of obtaining the resources required to provide an adequate community service. Doctors still remain special advocates for chronic patients and must press for the development of proper alternative facilities before mental hospitals are closed.

\section{Role of rehabilitation condtant in poychiatric services}

(a) There should be a consultant with designated responsibility for rehabilitation in every District. The number of sessions allocated will depend on local need. Sessions must be available for the advisory, training and planning functions as well as the clinical function and other service commitments, eg for acute work, must be adjusted to allow for the rehabilitation commitment.

(b) The consultant should have an advisory role in relation to health and social services and to voluntary agencies, which should be included in the sessional allocation.

(c) The consultant should be responsible for developing those psychiatric services required for rehabilitation and the management of chronic mental disorder throughout the District.

(d) The consultant with special responsibility should have a variety of suitable facilities, staffed by multidisciplinary teams.

(e) The consultant should have clinical responsibility for those patients in rehabilitation facilities. He/she may act on an agency basis for colleagues, returning patients to their care if and when appropriate. Alternatively, he/she may act in an advisory role to colleagues undertaking management of chronic patients.

(f) The consultant should be responsible for training of staff in rehabilitation procedures. 